\title{
Modeling cuttlefish behavioural chromatophore response
}

Zach Zboch*, James Peterson

From Twenty First Annual Computational Neuroscience Meeting: CNS*2012

Decatur, GA, USA. 21-26 July 2012

We build a model of cuttlefish chromatophore excitation patterns due to environmental input. Specific inputs generate scripted chromtophore pattern responses on the surface of the skin. More complicated responses are then assembled from these templates as sequences of inputs arrive. We build a simplistic cuttlefish brain

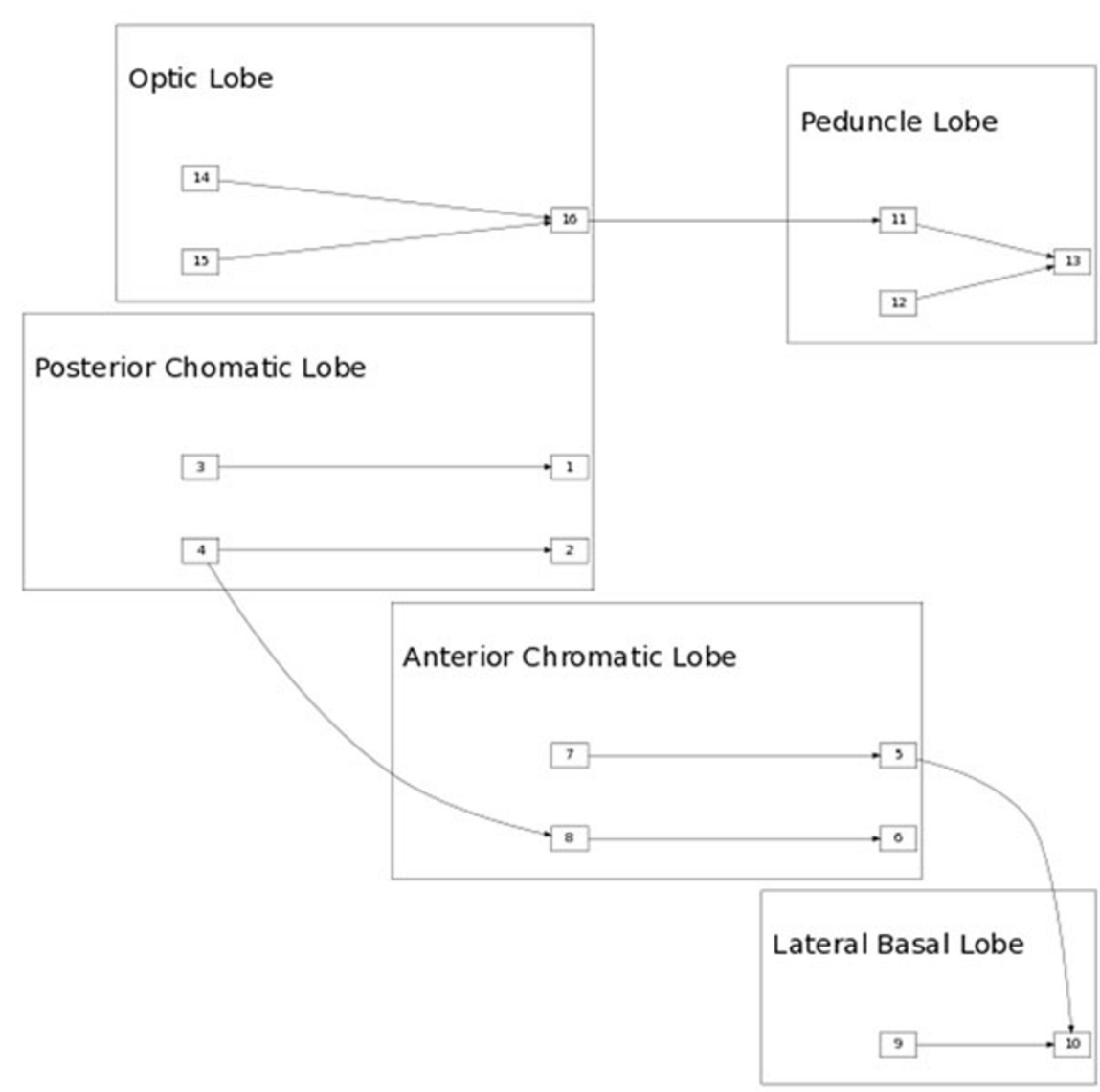

Figure 1 Cuttlefish chromatophore processing 
using neural architecture modeling tools written in MatLab which allow us to construct the brain model from individual modules using a vector addressing scheme [1] (Figure 1).

Inputs come into the sensory input module and are processed by the cuttlefish brain architecture into signals sent to the output module. The signals activate the individual chromatophores in the usual way giving an essentially binary on/ off pixel response. Different cues in the environment are mapped to known cuttlefish pigmentation overlays on the surface of the skin. Individual simple cues result in coarse patterns of chromotophore activation and upon receiving a sequence of simple cues, more complicated responses are constructed in a hierarchical fashion [1].

The chromatophore visibility is known to be due to a brain signal which when received energizes a ring of muscle which contracts and pushes a dot of ink up to the surface of the skin. Hence, activation signals lead to visible dots and lack of activation signal can be inferred from the loss of the pigment dot. Our model therefore treats each chromatophore as a binary switch which moves from 1 to 0 or vice versa depending on the signal sent to the output module from our cuttlefish brain processing $[3,4]$.

Published: 16 July 2012

\section{References}

1. Peterson JK: Bioinformation Processing: A primer on cognitive modeling volume one.[http://www.lulu.com].

2. Messenger JB: Cephalopod chromatophores: neurobiology and natural history. Biol. Rev 2001, 76:473-528.

3. Parker GH: Animal Colour Changes and their Neurohumours: A survey of investigations 1910 - 1943. Hafner Publishing Company, NY; 1971.

4. Bagnara JT, Hadley ME: Chromatophores and Color Changes: the comparative physiology of animal pigmentation. Prentice-Hall, Inc., New Jersey; 1973

doi:10.1186/1471-2202-13-S1-P4

Cite this article as: Zboch and Peterson: Modeling cuttlefish behavioural chromatophore response. BMC Neuroscience 2012 13(Suppl 1):P4.

\section{Submit your next manuscript to BioMed Central} and take full advantage of:

- Convenient online submission

- Thorough peer review

- No space constraints or color figure charges

- Immediate publication on acceptance

- Inclusion in PubMed, CAS, Scopus and Google Scholar

- Research which is freely available for redistribution

Submit your manuscript at www.biomedcentral.com/submit 